\title{
Buddhism and Subjective Wellbeing: Do Self-Esteem, Optimism and Perceived Control Play a Role?
}

\author{
Lufanna Ching-Han Lai \\ School of Psychology, Gratia Christian College, Hong Kong, China \\ Email: lufanna@yahoo.com.hk
}

Received 13 July 2015; accepted 12 September 2015; published 18 September 2015

\begin{abstract}
This study investigated the relationship between Buddhism and subjective wellbeing within the theoretical framework of a revised homeostatic model of subjective wellbeing (SWB). This model integrates the affective (homeostatically protected mood: content, happy and excited), cognitive (self-esteem, optimism and perceived control: primary control and secondary control) and experiential factors in relating to SWB. Given that the religious doctrine of Buddhism advocates selflessness and self-attained liberation from suffering, it is predicted that, among the cognitive factors, primary control and optimism will predict more significant SWB variance beyond the other homeostatic model factors than self-esteem. Additionally, compared with those without religious belief, the Buddhists would be higher in SWB, primary control and optimism, but lower in self-esteem. Chinese samples were drawn in Hong Kong comprising 153 Buddhists and 240 participants without religious belief. Through the use of questionnaire, it was found that, quite contrary to prediction, secondary control and self-esteem explained significant SWB variance for the Buddhists while none was provided by primary control and optimism. Also, no significant intergroup difference was found on SWB and all cognitive factors. The results were discussed in terms of difficulty in the eradication of egocentric mentality.
\end{abstract}

\section{Keywords}

Subjective Wellbeing, Buddhism, Self-Esteem, Optimism, Primary Control

\section{Introduction}

According to Buddhism, life is filled with sufferings and the ultimate goal of Buddhism is to teach individuals how to put an end to their sufferings as well as the ways to pursue happiness [1] [2]. Buddha means the "enlightened one", in that one is completely free from faults and mental obstructions, and sees things as they really are [3]. According to Buddhist teaching, people should be enlightened to the three basic characteristics of all phenomena: impermanence, dissatisfactoriness and selflessness in order for them to liberate from sufferings [3] [4]. Thus, enlightenment is the only way that leads to attainment of real and lasting happiness [3]. Moreover, every- 
one has the potentiality to enter the path of enlightenment and becomes a Buddha [3].

There are different branches of Buddhist belief such as Mahāyāna, Theravāda and Vajrayāna. In Hong Kong, Mahāyāna Buddhism is dominant. The objective of this study is to investigate, in the situation of Hong Kong, the relationship between Buddhism and subjective wellbeing (SWB) within the theoretical framework of a revised homeostatic model of SWB, which integrates the affective (content, happy and excited), cognitive (self-esteem, optimism and perceived control) and experiential factors in relating to SWB [5].

\section{Literature Review}

\subsection{Normative Levels of Subjective Well-Being}

SWB can be defined as the affective and cognitive evaluation people make about how happy and satisfied they are with their lives [6]-[8]. Within psychology, cumulative studies support the view of SWB as relatively stable and moderately positive [9]-[11]. For example, Cummins [12] combined the population means from 16 life satisfaction studies conducted in Western nations. Data were standardized to a statistic called the percentage of scale maximum (\%SM) which converts scale scores into a range from 0 to 100 . Using the mean values from each survey as data yielded a mean of 75 points and a standard deviation (SD) of 2.5. Hence, the normative SWB range is $70 \%-80 \%$ SM. However, inclusion of survey means from non-Western nations revealed that the mean of SWB was 70 (SD = 5), thus causing the normative range to expand downward, to 60\% - 80\% SM [13]. This downward expansion may be due to poverty and disadvantage in economically underdeveloped countries and/or the influence of cultural response bias acting particularly within Confucian-based cultures [14].

\subsection{Subjective Wellbeing Homeostasis}

In order to explain the stable positivity of SWB as described, a revised homeostatic model of SWB is used (See Figure 1 below).

The affective factor of homeostatically protected mood (HPMood) is a construct that evolved from Russell's [15] conception of core affect. Similar to core affect, HPMood exists without reference to objects or events [16]. It is proposed as a genetically determined, constant positive affective background, that pervades many thought processes but most especially those that are evaluative of personal and general characteristics. The archetypical form of such evaluative is "How satisfied are you with your life as a whole?" It is found that the response to this item to be heavily saturated with HPMood [17]. Based on the above conceptualization and use of structural equation modelling, Davern et al. [17] found HPMood to comprise three affects as: content, happy and excited. They also proposed that HPMood was the basis of SWB set-point and positive mood that is defended by homeostasis. The domination of SWB by HPMood has also been confirmed by [18] [19].

Regarding the three cognitive buffers of self-esteem, optimism and perceived control, they are not only strongly perfused with HPMood but also have a cognitive component which is responsible for adjusting each buffer in order to defend HPMood [20]. That is, they are in intimate interaction with momentary experience and assist in the process of defending HPMood against life experiences [21].

With reference to Figure 1, the way Buddhism affects SWB will be discussed in terms of primary control, optimism and self-esteem.

Perceived Control: Perceived control refers to individual's perceived ability to change a situation and overcome challenges to achieve a desired outcome [22]. This can be gained through primary control by influencing existing physical, social or behavioral realities to fit their perceptions, goals or wishes [19], or by secondary control which brings themselves into line with the realities [22]. It is likely that the Buddhist teaching mainly increases primary control and thereby promoting SWB as follows:

Primary Control: The Buddhist teaching provides the means for adherents to liberate themselves from sufferings and realize happiness which can be achieved entirely out of their own will and effort. Some examples are cited. Nirvana is believed as an enlightened state characterized by peace and deep spiritual joy [4]. By practicing the Eightfold Path, people can undergo self-transformation in intellectual, emotional and moral aspects which in turn help transit to Nirvana [23]. Moreover, the belief in Karma, depicted as the result of willful intention [23], allows the Buddhists to determine their own wellbeing. That is, virtuous action will result in good karma which is in turn the main cause of happiness and good fortune in life (Gyatso, 1992). For instance, having good health, comfortable living conditions, harmonious relationship and success in activities are the results of previous good karma [3]. Conversely, all the sufferings people experience in life such as sickness, poverty, conflicts and accidents 
First order determinants as HPMood
Second order

determinants

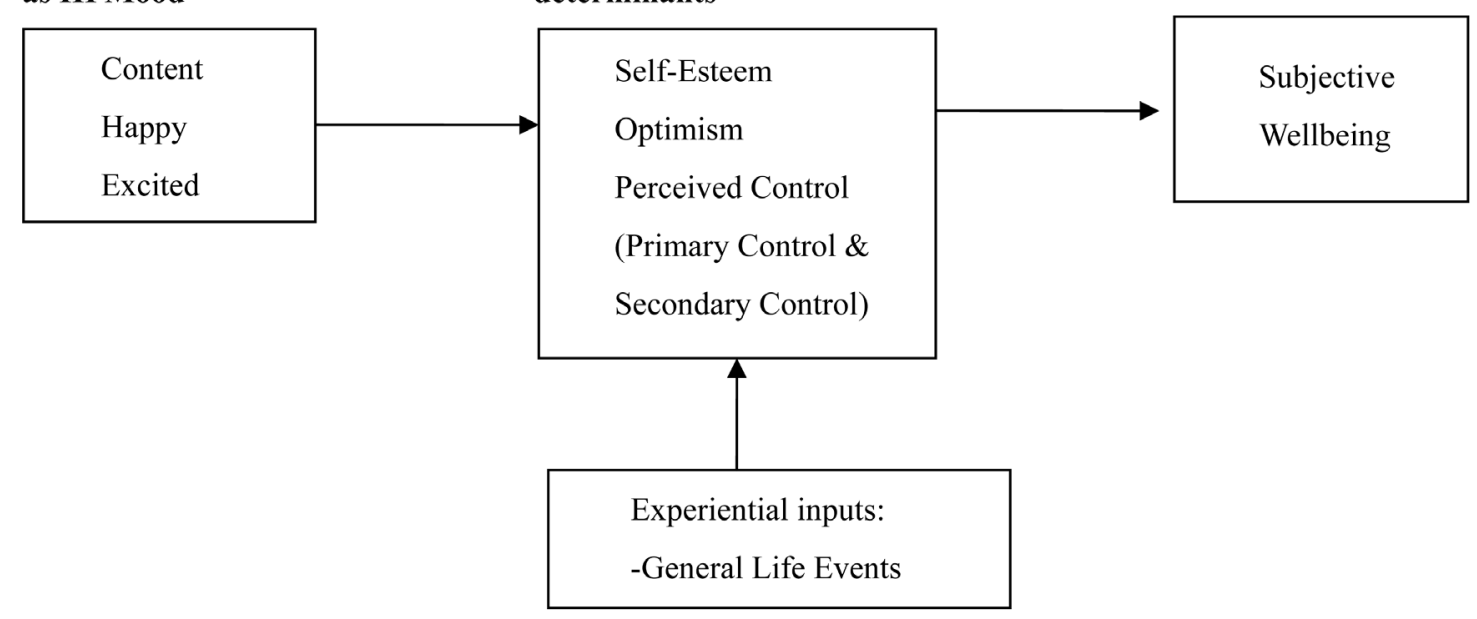

Third order determinants

as experiential input

Figure 1. A revised homeostatic mode l of subjective wellbeing [5].

are the results of their past bad karma [3]. Additionally, karma determines reincarnation in that good karma allows rebirth in upper realms as human beings or being in paradise; while bad karma leads to rebirth in lower realms as animals or being in hell [3]. In short, given that Buddhist teaching allows the adherents to exert high level of control on the quality of their present life as well as future being, primary control rather than secondary control, is more relevant in enhancing their SWB.

Optimism: Optimism refers to the perception that the future will be to the perceivers' advantage or for their pleasure [24]. As abovementioned, given that the Buddhist teaching provides the knowledge and means to take action in guarding themselves against potential misfortune as well as securing a blissful future, it is likely that the Buddhists are optimistic.

Self-Esteem: It refers to the degree to which an individual experiences oneself as worthy and capable [25]. It is generally agreed that self-esteem is a strong predictor of SWB (e.g. [26]-[28]); however, as Buddhism espouses the notion of selflessness and points out that the belief in a permanent self is the source of suffering [3] [4] [23], it is predicted that no close relationship is expected between them for the Buddhists. Buddhism states that the belief in a permanent self will lead to the development of self-centeredness which in turn arouses craving [3]. Craving, in Buddhism, is understood as the self-centered desire of an individual to be possessive and dominant [3], which in turn motivates people to relate to others in a selfish and egoistic manner, destroys the harmonious social relationship, thus providing the psychological basis for social conflict [3] [23]. Moreover, from the karmic point of view, these cravings result in bad karma, which in turn cause sufferings in life and unhappy rebirth [23]. Hence, in order to help release from suffering and enhance wellbeing, the Doctrine of Emptiness, a belief in the void of real existence and inherent reality [3] [4], is advocated by the Buddhists. For example, it is believed that the constituents of selfhood are the "Five Aggregates" in that human can be analyzed into the five factors of individuality with nothing left over [4]. It therefore helps people eradicate the selfgrasping ignorance and destroy the craving for possession and dominance. In short, Buddhism teaches that ego is the root cause of human sufferings and therefore people should develop self-renunciation to eradicate the self-grasping mentality which then creates an enduring state of wellbeing. In line with the above reasoning, it seems that the wellbeing of Buddhists is not dependent on self-esteem.

In sum, the SWB of Buddhists seems to be intimately and positively related to primary control and optimism but no close relationship is expected with self-esteem. Hence, it is hypothesized that, compared with those without religious belief, the Buddhists will score higher in SWB, primary control and optimism but lower in self-esteem. Additionally, it is hypothesized that for the Buddhists, primary control and optimism will predict 
more significant SWB variance beyond the other homeostatic model factors than self-esteem.

\section{Methods}

\subsection{Participants}

Through convenience sampling and direct recruitment from Buddhist organizations, 153 Buddhists and 240 participants without religious belief were drawn. These 393 Chinese samples participated in a survey by completing a questionnaire. The demographic characteristics of these two groups are that: In terms of gender, majority respondents are female (Buddhists: $72 \%$; those without religious belief: $55 \%$ ). Both groups are moderately highly represented by respondents from the age group of 36 - 55 (Buddhists: 66\%; those without religious belief: 50\%). With respect to income distribution (high: 20,001 \& above; middle: 15,000 - 20,000; low: 14,999 or less) [29], most are from high income group (Buddhists: $44 \%$; those without religious belief: $45 \%$ ), and the proportions for middle and low income group are quite equally distributed for both groups.

\subsection{Measures}

SWB: It was measured by the Personal Wellbeing Index (PWI) [30]. The scale consists of eight items measuring satisfaction with domains as: standard of living, health, achievement, relationships, safety, community-connectedness, future security and spirituality-religion. The mean of the domain scores derived from PWI constitutes a measure of SWB. The reliability coefficient for the current study was .88.

HPMood: It was measured by asking participants to indicate how each of the three affects of content, happy and excited described their feelings when they thought about their life in general. The coefficient alpha of 0.85 was obtained in this study.

Experiential Input: General life events were measured by asking participants whether anything had happened recently that caused them to feel happier or sadder than normal. Participants were asked to respond to three categories of response: "yes, happier" = 3 , "no" = 2 and "yes, sadder" $=1$.

Perceived Control: A six-item scale was developed as a measure of primary and secondary control, which was extracted from [31] which originally consists of nine items including the measure of relinquished control. The coefficient alpha of 0.83 was obtained in this study.

Optimism: The Life Orientation Test-Revised (LOT-R) [32] was used. LOT-R consists of six questions framed either in an optimistic or pessimistic fashion. This survey only used the three optimistically framed questions. In this study, the reliability coefficients reported for this three-item scale was 0.79 .

Self-Esteem: The ten-item Rosenberg Self-Esteem Scale [25] was used and the coefficient alpha reported in this study was 0.78 .

\section{Results}

Hypothesis 1: Compared with those without religious belief, the Buddhists will score higher in SWB, primary control and optimism but lower in self-esteem.

This hypothesis was tested by performing t-tests. Although it is predicted that Buddhist teaching is not relevant in enhancing secondary control, the same analysis was also performed on this variable for reference purpose. The results are provided in Table $\mathbf{1}$ as follows:

The results revealed that no significant intergroup difference was found for all variables.

Hypothesis 2: For the Buddhists, primary control and optimism will predict more significant SWB variance beyond the other homeostatic model factors than self-esteem.

Hierarchical multiple regression was performed with life events and HPMood entered in Model 1 and primary control, optimism and self-esteem in Model 2. Same as Hypothesis 1, secondary control was also included in the analysis for reference purpose. All assumptions are satisfied prior to the conduct of analysis. For the purpose of comparison, the same analysis was done with those without religious belief. A summary of results is provided below in Table 2:

Contrary to prediction, in Model 2, primary control and optimism did not contribute any significant Buddhists' SWB variance beyond the other homeostatic model factors, whereas secondary control and self-esteem respectively explained $7 \%$ and $8 \%$ significant SWB variance. 
Table 1. Comparison of Buddhists and those without religious belief on the measured variables.

\begin{tabular}{|c|c|c|c|c|c|c|c|c|c|c|}
\hline \multirow{2}{*}{ Groups } & \multicolumn{2}{|c|}{ SWB } & \multicolumn{2}{|c|}{ Primary Control } & \multicolumn{2}{|c|}{ Secondary Control } & \multicolumn{2}{|c|}{ Optimism } & \multicolumn{2}{|c|}{ Self-Esteem } \\
\hline & Mean & SD & Mean & SD & Mean & SD & Mean & SD & Mean & SD \\
\hline Buddhists & 65.92 & 12.20 & 71.63 & 15.53 & 74.42 & 16.38 & 69.04 & 14.77 & 61.42 & 13.25 \\
\hline $\begin{array}{c}\text { Without Religious } \\
\text { Belief }\end{array}$ & 65.61 & 12.51 & 74.29 & 13.21 & 71.45 & 16.38 & 66.92 & 16.80 & 61.93 & 12.40 \\
\hline $\begin{array}{c}\text { t-test } \\
\text { each column }\end{array}$ & \multicolumn{2}{|c|}{$\begin{array}{c}\mathrm{t}(344)=-0.22 \\
\mathrm{p}=0.825\end{array}$} & \multicolumn{2}{|c|}{$\begin{array}{c}\mathrm{t}(382)=1.79 \\
\mathrm{p}=0.074\end{array}$} & \multicolumn{2}{|c|}{$\begin{array}{c}\mathrm{t}(387)=-1.72 \\
\mathrm{p}=0.086\end{array}$} & \multicolumn{2}{|c|}{$\begin{array}{c}t(376)=-1.26 \\
p=0.208\end{array}$} & \multicolumn{2}{|c|}{$\begin{array}{c}t(364)=0.37 \\
p=0.713\end{array}$} \\
\hline
\end{tabular}

Note: SWB for the Buddhists was the average of 8 life domains while that for those without religious belief was the average of 7 domains excluding spirituality-religion.

Table 2. A summary of hierarchical regression analyses for Buddhists and those without religious belief.

\begin{tabular}{|c|c|c|c|c|c|c|c|c|}
\hline & \multicolumn{4}{|c|}{ Buddhists } & \multicolumn{4}{|c|}{ Without Religious Belief } \\
\hline & $\beta$ & $s r^{2}(\%)$ & $R^{2}$ & $\Delta R^{2}$ & $\beta$ & $s r^{2}(\%)$ & $R^{2}$ & $\Delta R^{2}$ \\
\hline \multicolumn{9}{|l|}{ Model 1} \\
\hline -Life Events & 0.02 & - & $0.29^{* * *}$ & & 0.03 & - & $0.39^{* * * *}$ & \\
\hline -HPMood & $0.54^{* * *}$ & $0.28(28)$ & & & $0.63^{* * *}$ & 0.39 (39) & & \\
\hline \multicolumn{9}{|l|}{ Model 2} \\
\hline -Life Events & 0.05 & - & $0.56^{* * *}$ & $0.28^{* * *}$ & 0.10 & - & $0.52^{* * *}$ & $0.13^{* * *}$ \\
\hline -HPMood & $0.20^{*}$ & $0.03(3)$ & & & $0.33^{* * *}$ & $0.05(5)$ & & \\
\hline -Primary Control & 0.11 & - & & & $0.18^{* *}$ & $0.02(2)$ & & \\
\hline -Secondary Control & $0.32^{* * *}$ & $0.07(7)$ & & & 0.04 & - & & \\
\hline -Optimism & 0.05 & - & & & 0.12 & - & & \\
\hline $\begin{array}{l}\text {-Self-Esteem } \\
\text { (SWB: DV) }\end{array}$ & $0.35^{* * *}$ & 0.08 (8) & & & $0.26^{* * *}$ & $0.05(5)$ & & \\
\hline
\end{tabular}

$s r^{2}(\%)$ : the percentage of unique variance explained. ${ }^{* * *} p<0.001 .{ }^{* *} p<0.01 .{ }^{*} p<0.05$. Note. SWB for the Buddhists was the average of 8 life domains while that for those without religious belief was the average of 7 domains excluding spirituality-religion.

\section{Discussion}

The results showed that there was no significant difference between the Buddhists and those without religious belief on SWB, perceived control (primary and secondary), optimism and self-esteem. Moreover, primary control and optimism failed to explain any significant SWB variance for the Buddhists. There are two possible explanations for these findings. Firstly, the teaching of Buddhism does not really benefit their followers in the sense of enhancing their control over life and optimism and thereby promoting their SWB. Secondly, the respondents have not fully benefited themselves from the Buddhist teaching. The later explanation seems easier to explain. Each religion is like a discipline having its own voluminous texts and treatises, as well as an organization having its specific code of conduct and creed. Hence, the devotion to religion may be understood as a longterm religious growth and development that necessitates constant effort in the continual pursuit of religious knowledge, and its practical application in regulating one's thought and behaviour. The eradication of egocentric mentality can be illustrated as an example.

As abovementioned, Buddhism teaches that the adherents should familiarize themselves with the Doctrine of Emptiness through continual practice and effort, which then gradually helps release the mind from the delusions of permanence and real self-existent and thereby resulting in liberation from sufferings and realization of happiness [3]. The wisdom of emptiness, which relates to a direct apprehension of the ultimate truth of all phenomena, is different from the worldly intelligence [3] [4]. For example, people may know a great many facts and understand complex technical subjects, but have no idea about how to maintain a peaceful mind and lead a virtuous 
life by means of the development of the wisdom of emptiness. In fact, the realization of such wisdom necessitates eliminating self-centeredness thinking and developing other-centeredness mentality. However, putting aside the self-oriented value and becoming other-oriented is difficult to achieve, as humans are so accustomed to the egocentric mentality, which is a commonly held value that they have long been developing during their growth. Hence, it will take tremendous effort and lengthy practice before the Buddhists can attain high level of religious maturity and then eradicate egocentric mentality.

Given the tremendous time and effort involved in attaining a radical change in value system, it therefore explains why the Buddhist samples did not score significantly higher than those without religious belief on SWB, primary control and optimism, as well as why primary control and optimism failed to account for significant Buddhists' SWB variance. In similar vein, the insignificant intergroup difference on self-esteem and the highest amount of Buddhists' SWB variance explained by self-esteem (8\%) may be accounted for in the way that the Buddhist samples might still attach to the mundane thinking that happiness is closely related to self-achievement and self-worthiness. Similarly, the finding that secondary control predicted the second highest amount of SWB variance (7\%) implies that the Buddhist samples might still have high tendency to exercise secondary control, rather than the primary control as acquired from Buddhist teaching, in handling life circumstances. For example, they might continually attribute uncontrollable events to chance and luck [9]. In a bid to verify whether religious maturity or commitment is the possible explanation to the above findings, further investigation is warranted by incorporating the measure of correlates such as Buddhists' length of conversion, level of commitment to religious teaching and other-orientation.

\section{References}

[1] Gethin, R. (1998) The Foundations of Buddhism. Oxford University Press, New York.

[2] Lopez, D.S. (2001) Buddhism: An Introduction and Guide. Penguin Press, London.

[3] Gyatso, G.K. (1992) Introduction to Buddhism. Tharpa Publications, London.

[4] Keown, D. (1996) Buddhism: A Very Short Introduction. Oxford University Press, New York.

[5] Lai, L.C.H. and Cummins, R.A. (2013) The Contribution of Job and Partner Satisfaction to the Homeostatic Defense of Subjective Wellbeing. Social Indicators Research, 111, 203-217. http://dx.doi.org/10.1007/s11205-011-9991-6

[6] Campbell, A., Converse, P.E. and Rodgers, W.L. (1976) The Quality of American Life: Perceptions, Evaluations, and Satisfactions. Russell Sage Foundation, New York.

[7] Cummins, R.A., Gullone, E. and Lau, A.L.D. (2002) A Model of Subjective Well-Being Homeostasis: The Role of Personality. The Universality of Subjective Well-Being Indicators, 7-46. http://dx.doi.org/10.1007/978-94-010-0271-4_3

[8] Diener, E. (2000) Subjective Well-Being: The Science of Happiness and a Proposal for a National Index. American Psychologist, 55, 34-43. http://dx.doi.org/10.1037/0003-066X.55.1.34

[9] Cook, V. (2002) A New Direction for Quality of Life: Evaluating the Comprehensive Quality of Life Scale as a Measure of Satisfaction and Depression. Australian Centre on Quality of Life, School of Psychology, Deakin University, Melbourne.

[10] Cummins, R.A. (2003) Normative Life Satisfaction: Measurement Issues and a Homeostatic Model. Social Indicators Research, 64, 225-256. http://dx.doi.org/10.1023/A:1024712527648

[11] Cummins, R.A., Lau, A.L.D., Mellor, D. and Stokes, M.A. (2009) Encouraging Governments to Enhance the Happiness of Their Nation: Step 1: Understand Subjective Well-Being. Social Indicators Research, 91, 23-36. http://dx.doi.org/10.1007/s11205-008-9324-6

[12] Cummins, R.A. (1995) On the Trail of the Gold Standard for Subjective Well-Being. Social Research Indicators, 35, 179-200. http://dx.doi.org/10.1007/BF01079026

[13] Cummins, R.A. (1998) The Second Approximation to an International Standard for Life Satisfaction. Social Indicators Research, 43, 307-334. http://dx.doi.org/10.1023/A:1006831107052

[14] Lai, L.C.H., Cummins, R.A. and Lau, A.L.D. (2013) Cross-Cultural Differences in Subjective Wellbeing: Cultural Response Bias as an Explanation. Social Indicators Research, 114, 607-619. http://dx.doi.org/10.1007/s11205-012-0164-z

[15] Russell, J.A. (2003) Core Affect and the Psychological Construction of Emotion. Psychological Review, 110, 145-172. http://dx.doi.org/10.1037/0033-295X.110.1.145

[16] Cummins, R.A. (2010) Subjective Wellbeing, Homeostatically Protected Mood and Depression: A Synthesis. Journal of Happiness Studies, 11, 1-17. http://dx.doi.org/10.1007/s10902-009-9167-0 
[17] Davern, M., Cummins, R.A. and Stokes, M. (2007) Subjective Well-Being as an Affective/Cognitive Construct. Journal of Happiness Studies, 8, 429-449. http://dx.doi.org/10.1007/s10902-007-9066-1

[18] Blore, J.D., Stokes, M.A., Mellor, D., Firth, L. and Cummins, R.A. (2011) Comparing Multiple Discrepancies Theory to Affective Models of Subjective Wellbeing. Social Indicators Research, 100, 1-16. http://dx.doi.org/10.1007/s11205-010-9599-2

[19] Tomyn, A.J. and Cummins, R.A. (2011) Subjective Wellbeing and Homeostatically Protected Mood: Theory Validation with Adolescents. Journal of Happiness Studies, 12, 897-914. http://dx.doi.org/10.1007/s10902-010-9235-5

[20] Cummins, R.A. and Wooden, M. (2014) Personal Resilience in Times of Crisis: The Implications of SWB Homeostasis and Set-Points. Journal of Happiness Studies, 15, 223-235. http://dx.doi.org/10.1007/s10902-013-9481-4

[21] Cummins, R.A. and Nistico, H. (2002) Maintaining Life Satisfaction: The Role of Positive Cognitive Bias. Journal of Happiness Studies, 3, 37-69. http://dx.doi.org/10.1023/A:1015678915305

[22] Weisz, J.R., Rothbaum, F.M. and Blackburn, T.C. (1984) Standing out and Standing in: The Psychology of Control in America and Japan. American Psychologist, 39, 955-969. http://dx.doi.org/10.1037/0003-066X.39.9.955

[23] Mitchell, D.W. (2002) Buddhism: Introducing the Buddhist Experience. Oxford University Press, New York.

[24] Peterson, C. (2000) The Future of Optimism. American Psychologist, 55, 44-56. http://dx.doi.org/10.1037/0003-066X.55.1.44

[25] Rosenberg, M. (1979) Conceiving the Self. Basic Books, New York.

[26] Piccolo, R.F., Judge, T.A., Takahashi, K., Watanabe, N. and Locke, E.A. (2005) Core Self-Evaluations in Japan: Relative Effects on Job Satisfaction, Life Satisfaction, and Happiness. Journal of Organizational Behavior, 26, 965-984. http://dx.doi.org/10.1002/job.358

[27] Ralph, A., Merralls, L., Hart, L., Porter, J.S. and Tan Su-Neo, A. (1995) Peer Interactions, Self-Concept, Locus of Control, and Avoidance of Social Situations of Early Adolescents. Australian Journal of Psychology, 47, 110-118. http://dx.doi.org/10.1080/00049539508257509

[28] Tong, Y. and Song, S. (2004) A Study on General Self-Efficacy and Subjective Well-Being of Low SES College Students in a Chinese University. College Student Journal, 38, 637-643.

[29] Census and Statistics Department (2006) 2006 Population By-Census-Summary Results. Hong Kong Government Printer, Hong Kong.

[30] International Wellbeing Group (2006) Personal Wellbeing Index-Adult (PWI-A).

[31] Chambers, S., Hollway, J., Parsons, E-R. and Wallage, C. (2003) Perceived Control and Wellbeing. 5th Australian Conference on Quality of Life, Melbourne.

[32] Carver, C.S. and Scheier, M. (2003) Optimism. In: Lopez, S.J. and Sydner, C.R., Eds., Positive Psychological Assessment: Handbook of Models and Measures. American Psychological Association, Washington DC. http://dx.doi.org/10.1037/10612-005 